\title{
Perceptions of Stress among Collegiate Aviation Flight Students
}

\author{
Michael F. Robertson and Lorelei E. Ruiz \\ Southern Illinois University Carbondale
}

\begin{abstract}
The purpose of this study was to identify student perceptions of stress caused by stressors unique to flight training. The study population consisted of students currently enrolled and actively flying in Aviation Flight courses. Students were administered a survey consisting of three general parts. The first part asked students to rate stressors that they faced and what effect they believe these have on their flight performance. The second part asked respondents to identify stress coping strategies that they employ. The third part requested basic demographic data. Analysis of the data was performed using SPSS version 17.0. Basic descriptive statistics were run, including frequencies, means, and standard deviations. The study found that students in the flight training program at Southern Illinois University Carbondale perceive checkrides/practical tests as the most stressful. This was followed by financial concerns. Other stressors that ranked as moderately stressful included written exams, flight course workload, checkride scheduling, and time management.
\end{abstract}

\section{INTRODUCTION}

Stress among college students has been a subject of interest for many years. Every student experiences stress throughout the course of a semester. According to Misra and McKean (2000), there are predictable times when stress levels can be higher than others, often caused by academic commitments and financial pressures. If a student perceives the stress negatively or the stress becomes extreme, a student's academic performance can suffer or they can experience adverse health effects (Misra \& McKean, 2000). Studies have identified sources of stress for college students (Ross, Niebling \& Heckert, 1999; Hirsch \& Ellis, 1996; Hudd, Dumlao, Erdman-Sager, Murray, Phan, Soukas, \& Yokozuka, 2000; Misra \& McKean, 2000). These stressors include but are not limited to academic work load, scholastic achievement, financial pressures, employment needs, time management and social readjustment as they transition to college life. Other studies related to stress have been conducted with commercial and military pilots (Stokes \& Kite, 1994). This study attempts to identify student perceptions of stress caused by stressors unique to flight training. The findings from this study may be used to identify which of these perceived stressors causes the greatest stress, and to recommend possible interventions or stress management programs for future flight students. The study answers the following research questions:

1. What aspects of a Collegiate Aviation Flight Training Program do students find most stressful?

2. How do Collegiate Aviation Flight Students believe stressors affect their flight performance?

3. What coping techniques do Collegiate Aviation Flight Students employ to deal with these stressors?

4. Are the coping techniques employed perceived by the Collegiate Aviation Flight Students to be constructive?

5. In what ways do the Collegiate Aviation Flight Students feel the program, department or university could help them with these stressors?

6. What effect, if any, does flight course level have on the perceptions of stress levels among students? 


\section{LITERATURE REVIEW}

Stress can be defined as the body's normal response to something that disturbs its physical, emotional or mental balance (Bruno, 2007). Stress is also described as a physiological or psychological reaction to a perceived threat that requires some action or resolution (Kottler \& Chen, 2008). Everyone experiences some form of stress on a regular basis. According to Karren, Hafen, Smith, and Frandsen (2002), while early research suggested that all stress was negative, it is now understood that a stressful situation can be from a positive or a negative experience. Having stress in your life can be healthy and positive; however, stress in excess can have negative effects physically and psychologically (Hall, n.d.). Stress is not limited to what goes on in our minds. Stress is a biological process that starts in two main systems in the body: the nervous system, which reacts to stress immediately, and the endocrine (hormone) system, which takes a longer period to react and can affect the body for longer periods of time causing exertion on the immune system (Karren, et al., 2002).

Many people think of stress as being a negative term. Hans Selye, an early stress researcher, introduced the terms eustress and distress to differentiate between positive and negative stress (Rice, 1992). Eustress can be defined as an experience that is pleasurable, satisfying, heightens awareness, increases mental alertness and promotes cognitive and behavioral performance, while distress is defined as an experience that is unpleasant, negative and painful that may cause anxiety, fear, worry or agitation and lead to a loss of productivity or health problems (Rice, 1992). Selye also recognized that having hyperstress, an excessive amount of stress that can overload the body, in one's life, was unhealthy, while having hypostress, not enough stress to keep one's body sharp and ready for action, was also unhealthy (Kottler \& Chen, 2008).

Stress can also be broken down into two main categories, short term (acute) and long term (chronic) stress. Short term stress is activated by a sudden threat or danger (Kottler \& Chen, 2008). An example of short term stress could be anything from an engine failure in flight to having to give an impromptu presentation in a college class. Short term stress does not usually cause any long term physical or psychological problems; often it is necessary to keep the body and mind in good working order (Kottler \& Chen, 2008). Long term stress, however, could cause the mind and body to break down over time. Long term stress would occur if a perceived threat or danger occurred over a longer period of time. An example of long term stress could sometimes be associated with a major life change such as changing of a major, new job or dealing with medical problems (Kottler \& Chen, 2008).

Karren, Hafen, Smith, \& Frandsen (2002) identify three types of stress: physical, psychological and psychosocial. Physical stress involves stressors in the environment such as noise, vibration, temperature extremes, prolonged exercise or an inadequate supply of oxygen. Psychological stress involves attitudes, feelings and our reaction to anything that we perceive as a threat. Flying could be an example of psychological stress, as one person may react to flying in a calm manner, whereas another may become stressed with the idea. Psychosocial stress involves relationships with people. This type of stress could involve conflicts with family or friends or a perceived threat to identity or self image.

College students, as a group, are particularly prone to stress. There have been studies concerning stress among college students (Ross, Niebling \& Heckert, 1999; Hirsch \& Ellis, 1996; Hudd et al. 2000; Misra \& McKean, 2000). These studies have identified sources of stress including academic workload, scholastic achievement, financial pressures, employment needs, time management and social readjustments as they transition to college life.

Ross, Niebling \& Heckert (1999) found that intrapersonal sources of stress were the most frequent source of stress among 100 college students surveyed. These included change in sleeping and eating 
habits, vacation, new responsibilities, increased workload, financial difficulties and change in social activities. Hudd et al. (2000) completed a study at Yale University using 145 students who were randomly selected. A relationship between stress and other health behaviors was one of the topics addressed in this study. The study concluded that students that perceived higher stress levels were less likely to practice healthy behaviors to deal with their stress.

Misra and McKean (2000) published a study with 249 undergraduate students. The students were asked about distinct areas such as, academic stress, time management, leisure satisfaction and anxiety. The authors found that the biggest source of academic stress was time management. The authors suggested that time management training be recommended by faculty and counselors more often.

It has been suggested that pilot performance can be affected by three different types of stress, which includes environmental stress, acute reactive stress and life stress (Stokes \& Kite, 1994). Life stress studies have been researched in the context of medical diagnosis since 1934. Holmes and Rahe of the U.S. Navy made initial attempts in the 1960's to develop a standardized quantitative approach in the evaluation of life stress events (Stokes \& Kite, 1994). Holmes and Rahe conducted scaling studies to determine the effects of various events on individual's lives. Holmes and Rahe developed a questionnaire called the Schedule of Recent Experiences (SRE), which contained forty-two questions concerning life changes, includeding subjects such as finances, health and domestic life. Each life event was given a weighting expressed in Life Change Units (LCUs). The SRE gave a total combined life change score based on the total number of LCUs tallied for any given year (Stokes \& Kite, 1994). In this study, health changes to the study population lagged behind the reported life crisis by about a year. In one study, four out of five people with scores over 300 reported injury or illness. Inversely, one in three reported injury and illness with scores between 150 and 199. This approach is overly simplistic given that it assumes that a life changing event has the same meaning for everyone (Stokes \& Kite, 1994). This study led to the Recent Life Change Questionnaire (RLCQ), which is a modified version of the SRE. Not only did this give a total score to the LCU but also to a Subjective LCU (SLCU), which allows the subject to rate the personal impact of the events. For example, a high value of LCUs with a low value of SLCUs indicates efficient coping by the individual (Stokes \& Kite, 1994).

In 1977, a US Navy psychologist, Dr. Robert Alkov and colleagues developed a 50 item questionnaire based on the work of Holmes and Rahe. Dr. Alkov suggested that life changes that affected the health of naval aviators could also result in aircraft accidents (Stokes \& Kite, 1994). In 1983, Dr. Alkov continued his research studies about life events in naval aviators, focusing on how these pilots were able to cope with stress and accidents. The results from these studies suggested that pilots that made more mistakes also were more likely to be having marital difficulties, personal relationship problems and were having trouble with their superiors and colleagues.

According to the Flight Safety Foundation (2006), in 1985 Dr. Alkov conducted a study of 700 U.S. Naval aviators who were involved in major aircraft accidents. Alkov found that 381 pilots that were involved in and at fault in major aircraft mishaps were more likely to have had problems with interpersonal relationships, which is a symptom of not coping well with stress. The other 356 aviators were not at fault in their aircraft mishaps (Flight Safety Foundation, 2006). Alkov found that there may be some personality factors that leave some pilots more susceptible to the negative effects of stress. Lack of maturity, inability to assess troublesome situations and having no sense of their limitations are all factors that are more prevalent in those who have been at fault in an aircraft accident (Flight Safety Foundation, 2006).

Other research has been done studying the effects of life stress and job related performance. Fiedler, Della Rocco, Schroeder, \& Nguyen (2000), conducted a study whereby they administered a questionnaire to 19 U.S. Coast Guard helicopter pilots. They found that as home stress increased, job stress also 
increased. "Pilots indicated that as the home stress experienced at work increased, self perceptions of flying performance decreased, especially the sense of not feeling ahead of the game." (p.7)

According to Fiedler, et al. (2000), Sloan and Cooper conducted a 1986 study of British commercial pilots looking at various sources of stress and coping mechanisms. They concluded that home stress has an effect on work through mental and cognitive consequences, such as, decreased concentration, recurring thoughts during periods of low workload and a tendency not to listen. They also concluded that actual flying performance was less affected by home based stress. Stress management for college students is very important. It is well documented that psychological stress and physical illness are related. Hall (n.d.) suggests that maintaining balance between social, personal and intellectual development are important for college students. Some of the stress coping strategies that Hall suggests are scheduling regular exercise, setting long term and short term goals, managing time and finding 20 minutes each day to relax. Meditation, self hypnosis, deep breathing exercises, deep muscle relaxation and massage are useful relaxation techniques. It is also helpful to think positively, add laughter and humor in your day and be communicative with your friends and family (Hall, n.d.).

When stress coping strategies appear to be inadequate, the result is more stress. Ultimately, this added stress can lead to self destructive behaviors such as, over eating, alcoholism, smoking and increased risk taking (Hall, n.d.). The Federal Aviation Administration (FAA) (1987) offers several techniques as well in managing long term life stress. These include implementing a physical fitness program, having a realistic assessment of yourself (knowing your limitations), avoiding stressful situations when possible and trying relaxation techniques as mentioned previously.

The stress coping strategies discussed by Hall (n.d.) and the FAA (1987) are universally accepted methods for handling stress. Because everyone experiences stress to some degree, it is important that the stress is channeled in healthy ways, before it affects your personal or professional life (Edkins \& Fowler, 2000).

\section{METHODOLOGY}

The study population consisted of students currently enrolled and actively flying in Aviation Flight courses at Southern Illinois University Carbondale. A total of 182 students, 168 male (92\%) and 14 female (7\%), were identified. A total of 83 surveys were returned to the researchers 76 male (92\%) and 7 female $(8 \%)$. This yielded a response rate of $43.9 \%$.

All flight instructors in the program were given enough cover letters and surveys for all of their flight students. The flight instructors were asked to distribute a cover letter and survey to each of their students. Students were to be instructed to fill out the survey and return it to the researcher's mailbox at the airport, or place it in one of two envelopes placed on the researchers' office doors.

The survey consisted of three general parts. The first part of the survey listed a variety of stressors that students in a collegiate aviation flight program could face. These were accompanied by a five-point Likert scale that the students were to use to gauge their perception of the amount of stress each stressor causes them, with $1=$ no stress to $5=$ severe stress. The survey allowed for respondents to add their own perceived stressors to the list and rate them also. Additionally, this portion asked students what effect they believe the stress has on their flight performance, and whether they believe there is anything the program/department/university can do to alleviate the stress.

The second part of the survey asked the students to identify stress coping strategies that they employ. They could choose from an existing list and indicate $\mathrm{Y}$ for yes or $\mathrm{N}$ for no. This portion of the survey 
allowed for respondents to add other coping strategies. Respondents were also asked whether they believe their stress coping strategies are constructive.

The final part requested basic demographic data. These included gender, age, current flight course, total flight time, number of lessons completed, and school year. Analysis of the data was performed using SPSS version 17.0. Basic descriptive statistics were run, including frequencies, means, and standard deviations.

\section{RESULTS AND ANALYSIS}

A total of 76 male flight students $(91.6 \%)$ and 7 female flight students $(8.4 \%)$ responded to the survey. Respondents ranged in age from 17 to 27 , with a median age of 20 years and a mean age of 20.4 years. Of the 83 respondents, 25 are in their first year of college, 16 are in the second year, 19 are in the third year, 20 are in the fourth year, and 2 reported having attended 5 years or more. One respondent did not indicate school year. The greatest percentage of respondents $(37.3 \%)$ indicated that they were in pre-solo primary training course. Of the remaining respondents, nine indicated post-solo primary training $(10.8 \%)$, nine indicated instrument training (10.8\%), 16 indicated commercial training $(19.2 \%)$, four indicated multi-engine training (4.8\%), and 11 indicated flight instructor training (13.2\%). One respondent did not indicate a flight course. See Table 1 for a further breakdown of respondents by course.

Flight time totals varied widely with respondents reporting as few as one flight hour to as many as 450 flight hours. Only two respondents did not report an estimation of their total flight time. The mean total flight time reported was 108.5 hours and the median total flight time reported was 70 flight hours.

Table 1: Breakdown of Respondents by Flight Course

\begin{tabular}{lc}
\hline Flight Course & n \\
\hline AF 199-Intermediate Flight/Program Transition & 2 \\
AF 201A-Primary Flight I & 31 \\
AF 201B-Primary Flight II & 9 \\
AF 203-Flight-Basic & 8 \\
AF 204-Flight-Intermediate & 4 \\
AF 206-Flight-Instrument & 9 \\
AF 207A-Flight Advanced & 4 \\
AF 207B-Flight Multi-Engine Operations & 4 \\
AF 300-Flight-Instructor (Airplane) & 10 \\
AF 301-Flight-Instructor (Airplane-Multi-Engine) & 1 \\
\hline
\end{tabular}

Note. Total number of respondents was 83 . One respondent did not indicate a flight course.

\section{Research Question 1. What aspects of a Collegiate Aviation Flight Training Program do students find most stressful?}

A total of 28 sources of stress were provided and students were asked to indicate on a 5 point Likert scale the magnitude of stress caused by each. The 5-point scale was anchored by the values $1=$ no stress, $3=$ moderate stress, and $5=$ severe stress. The two most stressful factors appear to be checkrides $(M=$ 
3.76) and financial factors $(M=3.39)$. These were the only two provided factors that were rated as more than moderately stressful. Other listed factors that were generally considered to be moderately stressful (mean rating greater than $M=2.5)$ included written exams $(M=2.92)$, flight course workload $(M=2.86)$, checkride scheduling $(M=2.67)$, and time management $(M=2.5)$. See Table 2 for complete rating rankings.

Table 2: Flight Student Ratings of Selected Stressors

\begin{tabular}{|c|c|c|c|}
\hline Stressor & Responses & $M$ & $S D$ \\
\hline Checkrides/Practical Tests & 77 & 3.7 & 1.23 \\
\hline Financial Resources & 83 & 3.39 & 1.38 \\
\hline Written Exams & 80 & 2.92 & 1.18 \\
\hline Flight Course Workload & 83 & 2.86 & .96 \\
\hline Checkride Scheduling & 77 & 2.67 & 1.19 \\
\hline Time Management & 83 & 2.54 & 1.15 \\
\hline Family Expectations & 82 & 2.43 & 1.26 \\
\hline Completion Agreements & 81 & 2.39 & 1.26 \\
\hline Peer Performance/Pressure & 82 & 2.30 & 1.02 \\
\hline Flying the Airplane & 83 & 2.27 & .99 \\
\hline Work & 81 & 2.27 & 1.22 \\
\hline Responsibility of Operating Equipment & 83 & 2.21 & 1.03 \\
\hline Aircraft Availability & 83 & 2.15 & 1.15 \\
\hline Flight Training Expectations (out of slot) & 82 & 2.12 & .93 \\
\hline Flight Slot/Scheduling & 83 & 2.09 & 1.06 \\
\hline Flying the Simulators & 80 & 2.00 & 1.00 \\
\hline ATC Interaction & 81 & 1.98 & .96 \\
\hline Program Policies/MOS & 82 & 1.93 & .92 \\
\hline Advisement and Registration & 81 & 1.93 & 1.02 \\
\hline Social Readjustment & 82 & 1.93 & .94 \\
\hline One on One Instruction & 82 & 1.89 & .94 \\
\hline Flight Instructor personality & 83 & 1.80 & 1.12 \\
\hline Certification Paperwork & 83 & 1.78 & .91 \\
\hline Transportation to/from airport & 83 & 1.57 & .87 \\
\hline Flight Instructor capability & 83 & 1.53 & .83 \\
\hline Housing & 82 & 1.46 & .74 \\
\hline Flight Instructor availability & 83 & 1.45 & .68 \\
\hline Support Staff & 83 & 1.36 & .61 \\
\hline
\end{tabular}


Eleven respondents also listed and rated at least one other stressor. Stressors listed by more than one respondent included Sports $(n=2, M=4.5)$ and Weather $(n=2, M=2.5)$. Other stressors included both personal and flight program-related factors. See Table 3 for a listing of these ratings.

Table 3: Other Stressors Reported by Flight Students

\begin{tabular}{lcc}
\hline Stressor & Responses & $\boldsymbol{M}$ \\
\hline Adapting to workload in bird & 1 & 5 \\
Flight instructor flexibility & 1 & 5 \\
Homework & 1 & 5 \\
No show fees & 1 & 5 \\
Recent loss in family & 1 & 5 \\
Time constraints & 1 & 5 \\
Sports & 2 & 4.5 \\
AF 206 (instrument training) & 1 & 4 \\
Getting enough sleep & 1 & 4 \\
Relationship & 1 & 4 \\
Timely completion of program & 1 & 3 \\
Weather & 2 & 2.5 \\
Afternoon weekend flying & 1 & 1 \\
\hline
\end{tabular}

\section{Research Question 2. How do Collegiate Aviation Flight students believe stressors affect their flight} performance?

The survey asked respondents the following question: "Do you think that the stressors you face as an Aviation Flight Student have a positive or negative effect on your flight performance? Explain.”

Thirty-five respondents $(42.2 \%)$ indicated that they believe the stressors have a positive effect while $15(18.1 \%)$ indicated that they believe the stressors have a negative effect. Twenty-four respondents $(28.9 \%)$ indicated that the effect depends on the stressor. Three $(3.6 \%)$ respondents indicated that the stressors have no effect on their flight performance. One respondent $(1.2 \%)$ was unsure of the effect that the stressors have on their flight performance. Five respondents $(6 \%)$ did not indicate an answer for this item.

\section{Research Question 3. What coping techniques do Collegiate Aviation Flight Students employ to deal with these stressors?}

A total of 22 activities were listed and respondents were asked to indicate, by circling Y or N, whether they engaged in each of the activities to relieve stress. They were also provided the opportunity to list two other stress-relieving activities. Respondents indicated that they are most likely to listen to music $(n=$ $78)$, talk to friends or family $(n=70)$, engage in outdoor activity $(n=69)$, watch television $(n=67)$, or sleep $(n=64)$. They indicated that they are least likely to smoke $(n=11)$, write in a journal $(n=11)$, meditate $(n=8)$, do yoga $(n=3)$, or abuse drugs $(n=0)$ to relieve stress. 
Sixteen respondents also listed at least one additional stress-relieving activity, and several of these reported more than one. These included specific outdoor sports or activities (12), organization techniques (3), playing a musical instrument (2), physical or emotional outbursts (2), drinking not to excess (1), and adult entertainment (1).

\section{Research Question 4. Are the coping techniques employed perceived by the Collegiate Aviation Flight Students to be constructive?}

The survey asked respondents the following question: "Would you consider the methods you choose to relieve stress to be constructive?" Fifty-five respondents indicated that they do believe their stress coping strategies are constructive, while nine indicated that they do not believe they are constructive, and 16 indicated that it depends. Three respondents did not answer the question.

\section{Research Question 5. In what ways do the Collegiate Aviation Flight Students feel the program, department, or university could help them with these stressors?}

Survey respondents were asked to reply to the following question: "Is there any way that the program/department/university could help alleviate any of these stressors? If so, how?" Students had a wide range of comments. Twenty-three respondents indicated that there was nothing more that the university could do to alleviate the stresses. Fourteen of the students did not respond to the question. Of the remaining responses, the majority of comments revolved around financial concerns (9), the stress of checkrides (5), the need for study groups (5), course completion concerns (4), and aircraft availability (4). Some of the responses seem to provide suggestions for general program or course improvement, rather than specific stress-relieving options/interventions. Table 4 lists the general responses to this question. 


\begin{tabular}{lc} 
Suggestion & Responses \\
\hline No change needed or Nothing & 23 \\
No response & 14 \\
Do more to address students' financial concerns & 9 \\
Reduce checkride stress & 5 \\
Provide study groups & 5 \\
Resolve course completion issues & 4 \\
Acquire more airplanes & 4 \\
Instructor personality issues & 3 \\
Provide more flight time/slots & 3 \\
Review Master Operations Syllabus policies & 3 \\
Improve communications/information dissemination & 3 \\
Hire more instructors & 2 \\
Require less weekend/out of slot flying & 2 \\
Require more weekend/out of slot flying & 2 \\
Provide other transportation options to airport & 2 \\
Improve flexibility regarding Talon/TCO & 2 \\
Improve checkride scheduling & 2 \\
Allow breaks during lessons & 1 \\
Improve counseling/advisement provided to students & 1 \\
Arrange commercial airline rides for students to observe & 1 \\
Improve relations with ATC & 1 \\
Start coursework more slowly & 1 \\
Address alcohol/substance abuse issues among some & 2 \\
\hline
\end{tabular}

Research Question 6. What effect, if any, does flight course level have on the perceptions of stress levels among students?

As the greatest percentage of respondents have only just begun their collegiate flight training at SIUC, the researchers were interested in what effect their responses have on the findings overall. Breaking down the data by flight course might also yield information that could lead to programmatic improvements for certain groups of students. For that reason, the researchers looked first at all respondents in aggregate, then at subgroups of respondents based on their reported current flight course. The MEI course is not considered for this analysis as there was only one student in the course at the time the survey was disseminated. 
The more noticeable differences occurred in the responses from the AF199 $(n=2)$ and AF201A $(n=$ 31) students. These are all students who are new to the flight training program; AF199 students are entering the program with a private pilot certificate, and AF201A students have a student pilot certificate.

Combined, the AF199 and AF201A students all tended to rate Checkride Scheduling and Completion Agreements as less stressful than did the other students. This may be due to the fact that these students have not had to deal with these issues while at SIUC. It should be noted that six AF201A students did not provide a rating for Checkride Scheduling, and two did not provide a rating for Completion Agreements.

Only two AF199 students responded to the survey. It is of interest to note that these students rated Family Expectations as the most stressful $(M=4.5)$ factor. This was followed by Checkrides/Practical Tests $(M=4.0)$, Peer Pressure $(M=3.5)$, and Social Readjustment $(M=3.0)$. While the Checkrides/ Practical Tests rating falls in line with the responses from the more advanced students, the rating for Peer Pressure and Social Readjustment was much higher than the other courses.

The AF201A students indicate a much lower stress level $(M=2.8)$ for Checkrides/Practical Tests than all other classes of students. One obvious reason for this could be that they have not yet been exposed to a checkride, and may not have a full grasp of what a checkride entails. It should be noted that six of the presolo primary students actually did leave this particular item blank.

There were also some differences in stress factor ratings reported by AF203 and AF204 students. AF203 and AF204 are the first and second stage of Commercial Pilot training. CFI capability was rated as causing more stress by students in AF203 $(M=2.25)$ and AF204 $(M=2.5)$, but the variations in responses were also higher among these groups $(S D=1.16$ for AF203, $S D=1.73$ for AF204). Flight Slot/Scheduling was rated as more stressful by AF204 students $(M=3.5)$. No other remarkable differences based on flight course alone were noted.

\section{RECOMMENDATIONS}

The purpose of this study is to identify student perceptions of stress caused by stressors unique to flight training. A further objective is to recommend possible interventions or stress management programs for future flight students.

From the students' comments, the researchers concluded that there are several things the program may want to consider to assist students in the future with their stress. Offering formal study groups and informal checkride question-and-answer sessions could help alleviate checkride stress. To address students' financial concerns, the program should continue to seek out new scholarship opportunities as well as increase the advertising of opportunities that currently exist. The program should also explore scheduling changes to improve aircraft availability.

The Social Readjustment scores for students transferring in to the program with a Private Pilot certificate indicate that some sort of initial indoctrination program may help. This type of program may also help incoming freshman students as well. Further discussion with these students may help determine whether the program can help with this, as no comments addressed this specifically. Possible topics that could be discussed in this program could include, but not be limited to, expected workload, course completion expectations, scheduling, time management and constructive stress coping techniques. These recommendations will be shared with the Department Chair, Chief Flight Instructor, and members of the senior faculty.

Future studies similar to this should be conducted, increasing the size of the study population to facilitate investigation of gender differences concerning stressors and coping techniques. Future studies 
should also focus on determining which specific stressors students perceive to have a negative effect on performance, as well as which coping techniques they perceive to be constructive. 


\section{REFERENCES}

Bruno, L. C. (2007). Stress reduction. In Encyclopedia of Medicine. 20010406. FindArticles.com. 14 Sep. 2007. http://findarticles.com/p/articles/mi_g2601/is _0013/ai_2601001306/?tag=content;col1

Edkins, G. \& Fowler, D. (2000). On the edge: How do you stop major life events affecting your performance on the flight deck? [Electronic version]. Flight Safety Australia, July-August 2000, 3033. Retrieved March 16, 2009, from http://www.casa.gov.au/ fsa/2000/jul/page30-35.pdf

Federal Aviation Administration (1987). Aeronautical decision making for student and private pilots (Report No. DOT/FAA/PM-86/41). Washington, DC Author. (NTIS No. ADA182549)

Fiedler, E.R., Della Rocco, P.S., Schroeder, D.J., \& Nguyen, K. (2000). The relationship between aviators home-based stress to work stress and self perceived performance (Report No. DOT/FAA/AM-00/32). Washington, DC: Office of Aviation Medicine.

Flight Safety Foundation. (2006, January-February). Accumulated stress presents range of health risks. Human Factors \& Aviation Medicine, 53(1).

Hall, G. (n.d.) College students and stress. Retrieved November 18, 2009 from https://www.cnr.edu/Media_Library/stress.pdf.pdf

Hirsch, J. K., \& Ellis, J. B. (1996). Differences in life stress and reasons for living among college suicide ideators and non-ideators [Electronic version]. College Student Journal, 30(3), 377-384. Retrieved November 18, 2009 from http://web.ebscohost.com/ehost/detail?vid=15\&hid=7\&sid=4e52f906-d21d44ce-87d4-75e46d63ce2a\%40sessionmgr104\&bdata=JnNpdGU9ZWhvc 3QtbG12ZSZzY29wZT1zaXRl\#db=hlh\&AN=9707062764

Hudd, Suzanne S., Dumlao, J., Erdman-Sager, D., Murray, D., Phan, E., Soukas, N., \& Yokozuka, N., (2000). Stress At college: Effects on health habits, health status and self-esteem [Electronic version]. College Student Journal. June 2000. FindArticles.com. 13 Feb. 2008. http://findarticles.com/p/articles/mi m0FCR/is 2 234/ai_63365177

Karren, K., Hafen B., Smith, N., \& Frandsen, K. (2002). Mind/body health: The effects of attitudes, emotions, and relationships ( $2^{\text {nd }}$ ed.). San Francisco: Benjamin Cummings.

Kottler, J. A. \& Chen, D. (2008). Stress management and prevention: Applications to daily life. Belmont, WA: Thomas Wadsworth.

Misra, R. \& McKean, M. (2000). College students' academic stress and its relation to their anxiety, time management, and leisure satisfaction [Electronic version]. American Journal of Health Studies, 16, 41-51.http://findarticles.com/p/articles/mi_m0CTG/is_1_16/ai_65640245/

Rice, P. L. (1992). Stress and health. Pacific Grove, CA: Brooks, Cole Publishing Company.

Ross, E. S., Niebling, B. C., \& Heckert, T. M. (1999). Sources of stress among college students [Electronic version]. College Student Journal. June 1999. FindArticles.com. 13 Feb. 2008. http://findarticles.com/p/articles/mi m0FCR/is 2 33/ai 62839434/

Stokes, A. \& Kite, K. (1994). Flight stress: Stress, fatigue and performance in aviation. Burlington, VT: Ashgate Publishing Company. 